\title{
BMJ Open Acceptability of and symptom findings from an online symptom check-in tool for COVID-19 outpatient follow-up among a predominantly healthcare worker population
}

To cite: Kerr C, 0' Regan S, Creagh D, et al. Acceptability of and symptom findings from an online symptom check-in tool for COVID-19 outpatient follow-up among a predominantly healthcare worker population. BMJ Open 2021;11:e050444. doi:10.1136/ bmjopen-2021-050444

- Prepublication history and additional supplemental material for this paper are available online. To view these files, please visit the journal online (http://dx.doi.org/10.1136/ bmjopen-2021-050444).

Received 23 February 2021 Accepted 25 August 2021

Check for updates

(C) Author(s) (or their employer(s)) 2021. Re-use permitted under CC BY-NC. No commercial re-use. See rights and permissions. Published by BMJ.

For numbered affiliations see end of article.

Correspondence to

Dr Colm Kerr;

colmkerr@gmail.com

\section{ABSTRACT}

Introduction Health systems worldwide have had to prepare for a surge in volume in both the outpatient and inpatient settings since the emergence of COVID-19. Early international healthcare experiences showed approximately $80 \%$ of patients with COVID-19 had mild disease and therfore could be managed as outpatients. However, SARS-CoV-2 can cause a biphasic illness with those affected experiencing a clinical deterioration usually seen after day 4 of illness.

Objective We created an online tool with the primary objective of allowing for virtual disease triage among the increasing number of outpatients diagnosed with COVID-19 at our hospital. Secondary aims included COVID-19 education and the promotion of official COVID-19 information among these outpatients, and analysis of reported symptomatology.

Methods Outpatients with acute COVID-19 disease received text messages from the hospital containing a link to an online symptom check-in tool which they were invited to complete.

Results 296 unique participants (72\%) from 413 contacted by text completed the online check-in tool at least once, generating 831 responses from 1324 texts sent. $83 \%$ of text recipients and $91 \%$ of unique participants were healthcare workers. $7 \%$ of responses to the tool were from participants who admitted to a slight worsening of their symptoms during follow-up. Fatigue was the most commonly reported symptom overall $(79 \%)$, followed by headache (72\%). Fatigue, headache and myalgia were the most frequently reported symptoms in the first 3 days of illness. $8 \%$ of responses generated in the first 7 days of illness did not report any of the cardinal symptoms (fever, cough, dyspnoea, taste/smell disturbance) of COVID-19. Participants found the tool to be useful and easy to use, describing it as 'helpful' and 'reassuring' in a follow-up feedback survey $(n=140)$. $93 \%$ said they would use such a tool in the future. $39 \%$ reported ongoing fatigue, $16 \%$ reported ongoing smell disturbance and $14 \%$ reported ongoing dyspnoea after 6 months.

\section{STRENGTHS AND LIMITATIONS OF THIS STUDY}

$\Rightarrow$ This tool saw a high level of uptake among those contacted $(72 \%)$, resulting in over 800 responses from almost 300 unique participants during the first wave of the COVID-19 pandemic in Ireland.

$\Rightarrow$ This research also features a follow-up of this cohort at 6 months from their initial diagnosis.

$\Rightarrow$ The tool required smartphone internet access to complete which may have disadvantaged older users.

$\Rightarrow$ The tool required a baseline level of technology literacy.

$\Rightarrow$ The online tool system at present only exists in English.

Conclusion The online symptom check-in tool was found to be acceptable to participants and saw high levels of engagement and satisfaction. Symptomatology findings highlight the variety and persistence of symptoms experienced by those with confirmed COVID-19 disease

\section{INTRODUCTION}

The COVID-19 pandemic poses a major obstacle to healthcare services across the globe. Originating in Wuhan, China, in late $2019{ }^{1}$ the WHO declared the outbreak to be a Public Health Emergency of International Concern on 30 January $2020^{2}$ and a pandemic on 11 March 2020. ${ }^{3}$ International healthcare experiences of SARS-CoV-2 infections show that approximately $20 \%$ of known patients with COVID-19 require inpatient admission. ${ }^{4-8}$ Thus approximately $80 \%$ of patients are classed as having mild disease and can be managed as outpatients.

SARS-CoV-2, however, can cause a biphasic illness in some patients. ${ }^{9}$ Those affected can experience a clinical deterioration usually 
seen between day 4 and day 9 of their illness, attributable to a form of cytokine storm ${ }^{510}$ and approximately $50 \%$ of patients with COVID-19 can develop shortness of breath or breathing difficulties during their illness. ${ }^{11}$ Such deteriorations in the disease course of outpatients with acute COVID-19 can lead to the need for clinical assessment and possible hospital admission. ${ }^{11}$

Health systems worldwide have been forced to make preparations for a surge in volume in both the outpatient and inpatient settings since the emergence of COVID$19{ }^{12}$ The increased demand placed on clinical capacity created several health system challenges as described and discussed by Judson et al. ${ }^{13}$ Firstly, provision of care to the patients who needed it most was made more difficult by front-line clinicians and healthcare staff spending a large proportion of their time on triage. Secondly, a surge of patients attending urgent care and primary care practices for advice placed a further burden on healthcare systems as well as potentially impacting on infection control management. Thirdly, constantly changing information and guidelines placed a strain on maintaining consistency in terms of medical recommendations.

Our centre, St. James's Hospital, is a large teaching hospital and tertiary referral centre located in Dublin, Ireland. The first case of COVID-19 at St. James's Hospital was diagnosed in early March 2020. Initially, patients with a diagnosis of COVID-19 who were not deemed to require inpatient admission were 'safety netted' on diagnosis by undergoing active monitoring via a telephone clinic operated by clinicians at St. James's Hospital. Patients received multiple phone calls over the course of their illness to assess the severity of their symptoms, their clinical progress, and their need for hospital assessment and inpatient admission if required. However, with exponentially increasing numbers of new COVID-19 diagnoses by midMarch 2020, this strategy of active telemedicine follow-up was no longer sustainable.

\section{AIM}

We created an online tool with the aim of allowing disease triage of outpatients diagnosed with COVID-19. The text and online tool contained the phone number of the hospital's clinician-led COVID-19 phone line. Outpatients were prompted to contact this phone number if they had any clinical concerns related to their acute illness, and to contact the emergency services should they be experiencing severe symptoms. Outpatients using the tool to report worsening symptoms of clinical concern were triaged, identified, and contacted by the hospital's COVID-19 outpatient team. The tool also aimed to promote patient education by providing a weblink to national COVID-19 related health information sources that the patient could access if they so wished.

Secondary aims of this tool included COVID-19 education and promotion of official COVID-19 among outpatients and analysis of their reported symptomatology.

\section{METHODS}

The online Typeform platform was used to create a short online tool (COVID-19 symptom check-in tool).

Outpatients, discharged inpatients and staff of the hospital with a PCR-proven diagnosis of COVID-19 were included in this survey. The date of symptom onset for each participant was entered into their electronic patient record. Text messages were sent from the hospital to participants at day 3 , day 6 , day 9 and day 12 of their illness. These dates were automatically calculated by using the participant's date of symptom onset, recorded on their electronic personal health record, as day 1 (if a participant received a PCR confirmed diagnosis of COVID-19 on the fourth day of their symptoms, the next text message they received would be on day 6 and they would receive just three messages (day 6, 9 and 12) in total). Only participants with a valid mobile phone number in their electronic records were able to receive text messages. The text contained a link to the online symptom check-in tool as well as a brief explanation of its purpose and the contact phone number for the dedicated clinician-led COVID-19 phone line that they could call if advice was required. The questions in the tool were arrived at by clinician consensus and adapted from the publications below which became available during the design period.

The tool (online supplemental material) consisted of 13 questions capturing basic patient information such as risk factors (adapted from Wu et $\mathrm{ll}^{14}$ ), duration and nature of COVID-19 symptoms (adapted from Chen et $a l^{15}$ ), temperature and pulse oximetry ${ }^{16}$ readings in the past 24 hours (if available), as well as an overall self-assessment of symptom progression since symptom onset. Two questions to assess the presence and severity of any breathing symptoms were adapted from the Greenhalgh et al publication on remote clinical assessment of patients with COVID-19. ${ }^{17}$ A short introductory and a conclusion page provided information on the hospital data privacy policy, a web link to the official national health service website for COVID-19 information (in multiple languages) as well as the contact phone number for the dedicated clinician-led COVID-19 phone line and the contact number for the emergency services should they be in extremis.

The text link to the online check-in tool was automatically sent to participants at 10:00 on the designated days. A clinician reviewed each response to the tool between 12:00 and 19:00 each day. Decisions to contact patients were made according to clinician assessment, considering the patient's reported symptoms, duration of illness, severity of symptoms and medical history. The check-in tool prompted patients to enter their date of birth, initials, and date of symptom onset. If a response led to clinical suspicion of patient deterioration in the community, the patient could be identified by cross-referencing the aforementioned identifiers with the hospital's electronic patient records, allowing them to be contacted and assessed by the clinician over the telephone. A decision could then be made to continue to monitor symptoms 
at home, link the patient in with further support services (such as home pulse oximetry), arrange a medical assessment at the hospital or advice to immediately contact the emergency services and/or present immediately to the emergency department.

A follow-up survey was sent 6 months later to all recipients of the initial text messages to evaluate feedback on their experience of the service. Six months follow-up was chosen so as to allow sufficient time to elapse since the onset of the patients' symptoms and to allow adequate time for reflection on the service. These findings are included in this paper.

\section{Patient and public involvement}

Patients and the public were not involved in any way with the design of this research.

\section{RESULTS}

From 2nd April to 7th June 2020, 1324 text messages were sent to 413 COVID-19 positive outpatients who had been diagnosed at St. James's Hospital, Dublin. These text messages led to 831 responses $(62.8 \%$ response rate) on the online COVID-19 symptom check-in. The average age of the 413 text recipients was 41 years (median 39 years), with ages ranging from 19 to 99 years. One hundred and twenty-nine $(31 \%)$ were males with $284(69 \%)$ females. Three hundred and forty-two $(83 \%)$ were healthcare workers. Two hundred and ninety-six unique participants $(72 \%)$ from the 413 contacted by text completed the online check-in at least once. The average age of these 296 patients was 37 years (median 35 years), with ages ranging from 19 to 81 years. Eighty (27\%) were males with $216(73 \%)$ females. Two hundred and sixty-nine of the respondents $(91 \%)$ were healthcare workers.

Of the 117 (28\%) who declined to respond to the online symptom check-in tool, the average age was 51 years (median age 51), with ages ranging from 21 to 99 years. Forty-eight $(41 \%)$ were males and $69(59 \%)$ females. Seventy-six $(65 \%)$ were healthcare workers. Using Wilcoxon rank-sum test (Mann-Whitney test), there was a statistically significant difference in the ages of participants who used the online symptom check-in tool versus those who did not, with older patients less likely to participate than younger patients $(p<0.01)$. Using $\chi^{2}$ testing, there was also a statistically significant difference among the genders $(\mathrm{p}<0.01)$ and healthcare worker status $(\mathrm{p}<0.01)$ in relation to their participation in the online symptom check-in tool, with males and nonhealthcare workers less likely to participate.

An anonymous feedback survey, to evaluate acceptability of the online check-in, was sent to the original 413 patients in December 2020. This survey received 140 responses (34\% response rate). Thirty-two (23\%) were males and $108(77 \%)$ were females. One hundred and sixteen $(83 \%)$ were healthcare workers. The age categories of these participants were recorded and can be viewed in figure 1 . Seventy-seven per cent of these respondents $(108 / 140)$ admitted to using the online check-in tool at least once between April and June 2020.

\section{Online check-in tool}

Twenty-one (7\%) of the online check-in participants had already spent at least one night in hospital due to COVID19 . Forty-one $(17 \%)$ were current or ex-smokers. Fiftynine $(20 \%)$ did not have access to thermometers at home and $225(76 \%)$ did not use pulse oximeters at home. The comorbidities of the cohort are shown in table 1 . Thirtythree $(11 \%)$ of participants had a history of asthma or chronic obstructive pulmonary disorder (COPD), with $20(7 \%)$ having hypertension and $11(4 \%)$ having a diagnosis of diabetes (table 1). Table 1 also reveals that 56 $(7 \%)$ of overall responses to the online check-in tool

\section{Age categories}

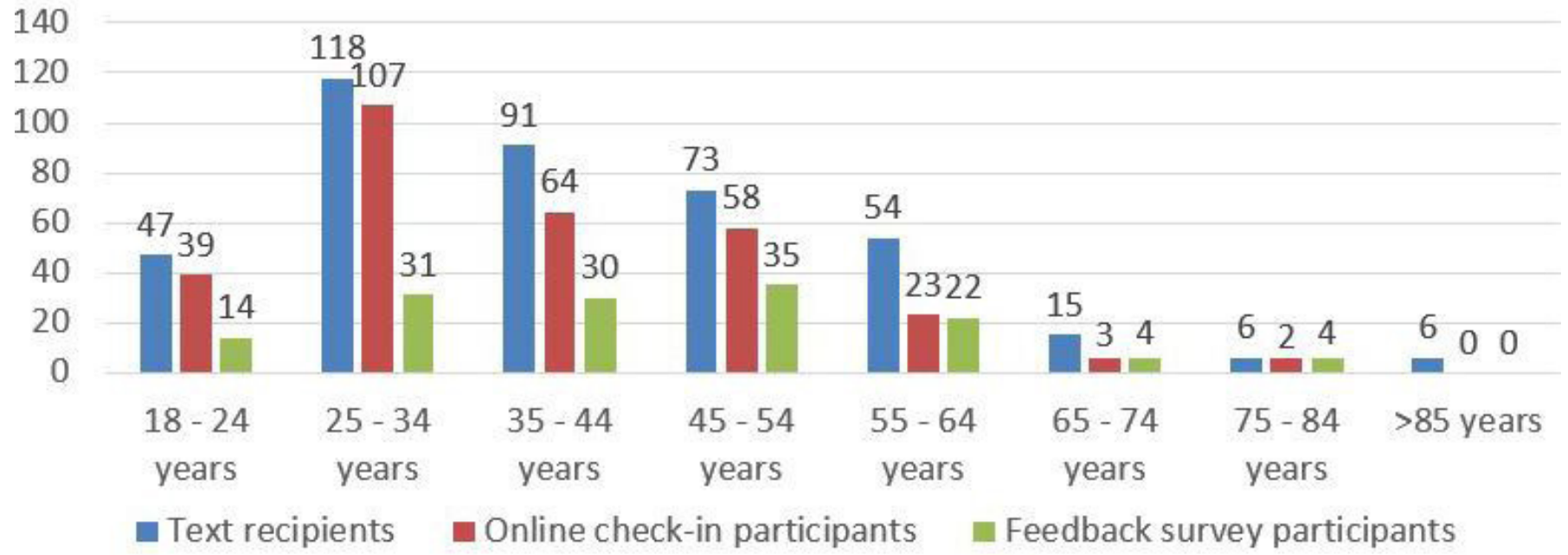

Figure 1 Age categories of participants who were sent texts from the hospital $(n=413)$, those who used the online COVID-19 symptom check-in tool $(n=296)$ and those who participated in the feedback survey $(n=140)$. 
Table 1 Demographics and comorbidities of those who participated in the online COVID-19 symptom check-in, as well as an overview of the 831 individual responses to the triage tool

\begin{tabular}{lll}
\hline $\begin{array}{l}\text { Online check-in tool } \\
\text { respondents }\end{array}$ & $\mathbf{n}$ & $\begin{array}{l}\text { Total } \\
\text { respondents } \\
\text { (total } \mathbf{n = 2 9 6 )}\end{array}$ \\
\hline
\end{tabular}

\begin{tabular}{lll} 
Gender & & \\
\multicolumn{1}{l}{ Male } & 80 & 27 \\
Female & 216 & 73 \\
Age & & \\
Average age (IQR) & $\begin{array}{l}37 \text { years (27- } \\
46 \text { years) }\end{array}$ & $\begin{array}{l}\text { Age range: } \\
19-81 \text { years }\end{array}$
\end{tabular}

Healthcare worker status

\begin{tabular}{lrr} 
Healthcare worker & 269 & 91 \\
\hline Non-Healthcare worker & 27 & 9 \\
\hline
\end{tabular}

Smoking status

$\begin{array}{lrr}\text { Smoker } & 17 & 6 \\ \text { Ex-smoker } & 34 & 11 \\ \text { Never-smoker } & 245 & 83\end{array}$

Symptom onset

\begin{tabular}{lrr} 
March 2020 & 100 & 34 \\
April 2020 & 164 & 55 \\
\hline May 2020 & 32 & 11 \\
\hline Already had an inpatient & 21 & 7 \\
admission due to COVID-19 & &
\end{tabular}

Comorbidities

\begin{tabular}{lcc} 
COPD/asthma & 33 & 11 \\
\hline Hypertension & 20 & 7 \\
\hline Diabetes mellitus & 11 & 4 \\
\hline Other endocrinopathies & 9 & 3 \\
\hline Ischaemic heart disease & 4 & 1 \\
\hline Immunosuppression & 3 & 1 \\
\hline Haematological disorder & 2 & 1 \\
\hline Active cancer diagnosis & 2 & 1 \\
\hline Neurological disorder & 1 & 0 \\
\hline Chronic kidney disease & 1 & 0 \\
\hline Chronic liver disease & 0 & 0 \\
\hline Individual responses & $\mathbf{n}$ & $\begin{array}{l}\text { Total } \\
\text { (total } \mathbf{n}=\mathbf{8 3 1} \text { respondents }\end{array}$
\end{tabular}

(\%)

\begin{tabular}{lcc}
$\begin{array}{l}\text { My symptoms have never } \\
\text { been bad }\end{array}$ & 98 & 12 \\
\hline $\begin{array}{l}\text { My symptoms have } \\
\text { improved }\end{array}$ & 461 & 55 \\
$\begin{array}{l}\text { My symptoms have stayed } \\
\text { the same }\end{array}$ & 216 & 26 \\
$\begin{array}{l}\text { My symptoms have } \\
\text { worsened a little }\end{array}$ & 56 & 7 \\
$\begin{array}{l}\text { My symptoms have } \\
\text { worsened a lot }\end{array}$ & 0 & 0 \\
\hline
\end{tabular}

Continued
Table 1 Continued

\begin{tabular}{lll}
\hline $\begin{array}{l}\text { Online check-in tool } \\
\text { respondents }\end{array}$ & $\begin{array}{l}\mathbf{n} \\
\text { (total } \mathbf{n = 2 9 6 )}\end{array}$ & $\begin{array}{l}\text { Total } \\
\text { respondents } \\
\text { (\%) }\end{array}$ \\
\hline $\begin{array}{l}\text { Self-report of some } \\
\text { tachypnoea/dyspnoea at rest }\end{array}$ & 80 & 10 \\
\hline $\begin{array}{l}\text { Self-report of some } \\
\text { tachypnoea/dyspnoea at } \\
\text { rest and worsening/no } \\
\text { improvement in symptoms }\end{array}$ & 37 & 4 \\
$\begin{array}{l}\text { Self-report of some } \\
\text { tachypnoea/dyspnoea at rest } \\
\text { and worsening of symptoms }\end{array}$ & 10 & \\
\hline
\end{tabular}

COPD, chronic obstructive pulmonary disorder.

indicated a slight worsening of symptoms during the course of their illness. No users of the tool reported a severe worsening of their symptoms. Ten responses $(1 \%)$ reported shortness of breath at rest in addition to a slight worsening of their symptoms. Of those who reported a worsening of their symptoms, seven individual participants were identified by the COVID-19 outpatient team as requiring in-person medical assessment, and three were subsequently admitted to the hospital.

Table 2 shows the symptoms reported by the responding participants at various time points. There were 831 responses in total to the online COVID-19 symptom check-in, with 85 responses from participants from days 1 to 4 of their onset of symptoms, 235 responses during days 5-8, 253 responses during days 9-12, 165 responses during days 13-16 and 93 responses from patients from 17 to 48 days after the onset of their symptoms (though participants only received text messages with the link to the online check-in tool on days 3, 6, 9 and 12 of their symptoms, they could access the link again at any time, and several accessed the link between 17 and 48 days after the onset of their symptoms).

The clinical criteria used in the European Centre for Disease Prevention and Control (ECDC) case definition of COVID-19 include one or more of the following symptoms: cough, fever, shortness of breath, and sudden onset of taste and/or smell disturbance. ${ }^{18}$ In our population, fatigue $(66 \%)$ was the most common symptom in the first 4 days of illness, followed by headache (53\%) and myalgia $(45 \%)$. The case criteria symptoms of cough $(40 \%)$, taste disturbance (39\%), smell disturbance (39\%), fever (13\%) and shortness of breath were the 4th, 5th, 6th, 16th and 19th most frequently reported symptoms, respectively, during this period.

The frequency of most reported symptoms remained static or decreased over time, with the exception of taste, smell disturbance and anorexia which peaked during days $5-8$ of symptoms at $49 \%, 50 \%$ and $26 \%$ respectively. Only $25 \%$ of participants reported full resolution of their symptoms at 16 days. 
Table 2 Frequency of symptoms reported to the online check-in tool during the course of illness

\begin{tabular}{|c|c|c|c|c|c|}
\hline Symptom & $\begin{array}{l}\text { Days } 1-4 \\
(n=85)(\%)\end{array}$ & $\begin{array}{l}\text { Days 5-8 } \\
(n=235)(\%)\end{array}$ & $\begin{array}{l}\text { Days } 9-12 \\
(n=253)(\%)\end{array}$ & $\begin{array}{l}\text { Days } 13-16 \\
(n=165)(\%)\end{array}$ & $\begin{array}{l}\text { Day } 17-48 \\
(n=93)(\%)\end{array}$ \\
\hline Fatigue & 66 & 56 & 55 & 45 & 41 \\
\hline Headache & 53 & 42 & 37 & 22 & 28 \\
\hline Myalgia & 45 & 31 & 23 & 10 & 19 \\
\hline Cough (dry/productive) & 40 & 44 & 45 & 41 & 38 \\
\hline Taste disturbance & 39 & 49 & 41 & 33 & 27 \\
\hline Smell disturbance & 39 & 50 & 45 & 33 & 30 \\
\hline Nasal congestion & 34 & 35 & 32 & 21 & 11 \\
\hline Dry cough & 29 & 32 & 31 & 28 & 32 \\
\hline Pharyngitis & 24 & 21 & 13 & 4 & 8 \\
\hline Anorexia & 21 & 26 & 20 & 12 & 14 \\
\hline Night sweats & 16 & 9 & 5 & 7 & 12 \\
\hline Coryza & 15 & 12 & 9 & 10 & 4 \\
\hline Rigors & 15 & 12 & 6 & 5 & 5 \\
\hline Dizziness & 13 & 14 & 9 & 7 & 2 \\
\hline Nausea & 13 & 13 & 11 & 8 & 4 \\
\hline Fever & 13 & 11 & 8 & 2 & 3 \\
\hline Productive cough & 12 & 14 & 17 & 16 & 5 \\
\hline Chest pain/tightness & 12 & 13 & 13 & 10 & 13 \\
\hline Dyspnoea & 9 & 11 & 11 & 10 & 13 \\
\hline Diarrhoea & 5 & 4 & 9 & 6 & 4 \\
\hline Vomiting & 1 & 2 & 0 & 2 & 0 \\
\hline Other & 0 & 1 & 1 & 1 & 1 \\
\hline No symptoms & 6 & 10 & 11 & 18 & 25 \\
\hline
\end{tabular}

$31 \%$ of responses to the tool came from participants during the first 7 days of their symptoms (259/831). Interestingly, of these 259 responses, $8 \%(22 / 259)$ did not report any symptoms of the ECDC case defining clinical criteria (cough, fever, shortness of breath, and sudden onset of taste and/or smell disturbance). Seventythree per cent $(16 / 22)$ of these responses reported fatigue, $55 \%(12 / 22)$ reported headache, $45 \%(10 / 22)$ reported myalgia, $41 \%(9 / 22)$ reported nasal congestion and 36\% (8/22) reported pharyngitis. Eighty-six per cent $(19 / 22)$ of these responses reported at least one of the following; headache, pharyngitis, nasal congestion and coryzal symptoms.

Figure 2 shows the range and frequency of all symptoms reported by participants during their initial illness between day 1 and day $48(n=296)$ as well as the symptoms reported by participants of the feedback survey 6 months later $(n=140)$. Fatigue was the most common symptom reported during the initial illness $(79 \%)$, followed by headache $(72 \%)$. The symptoms that meet the case definition criteria for COVID-19 (cough, taste disturbance, smell disturbance, fever and dyspnoea) were the $3 \mathrm{rd}, 5$ th, 6th, 8th and 14th most frequent symptoms at $66 \%, 59 \%, 58 \%, 49 \%$ and $31 \%$, respectively. After 6 months, only $39 \%$ of participants reported being symptom free. Thirty-nine per cent reported ongoing fatigue, $16 \%$ reported ongoing smell disturbance and $14 \%$ reported ongoing dyspnoea.

\section{Feedback survey}

One hundred and forty participants responded to the feedback survey in December 2020. Seventy-nine per cent $(111 / 140)$ were college/university educated. Sixty-one per cent $(86 / 140)$ were diagnosed with COVID-19 in April 2020, 31\% (43/140) in March and 8\% (11/140) in May. Sixteen per cent $(23 / 140)$ of respondents to this feedback survey were admitted to the hospital for at least 24 hours during their initial acute illness.

Figure 3 shows that $79 \%(111 / 140)$ of participants did not feel inconvenienced by receiving text messages from the hospital, and $77 \%(108 / 140)$ used the online COVID-19 symptom check-in at least once. (Of the 29 participants who felt inconvenienced by the texts, $76 \%$ (22/29) used the online check-in tool at least once.) Fifty-three per cent $(74 / 140)$ called the COVID-19 phone line during the course of their illness (this was the phone number contained in the text from the hospital and also highlighted in the online check-in tool). Twenty-one per cent (29) received a pulse oximeter from the hospital for remote $\mathrm{SpO} 2$ monitoring. 


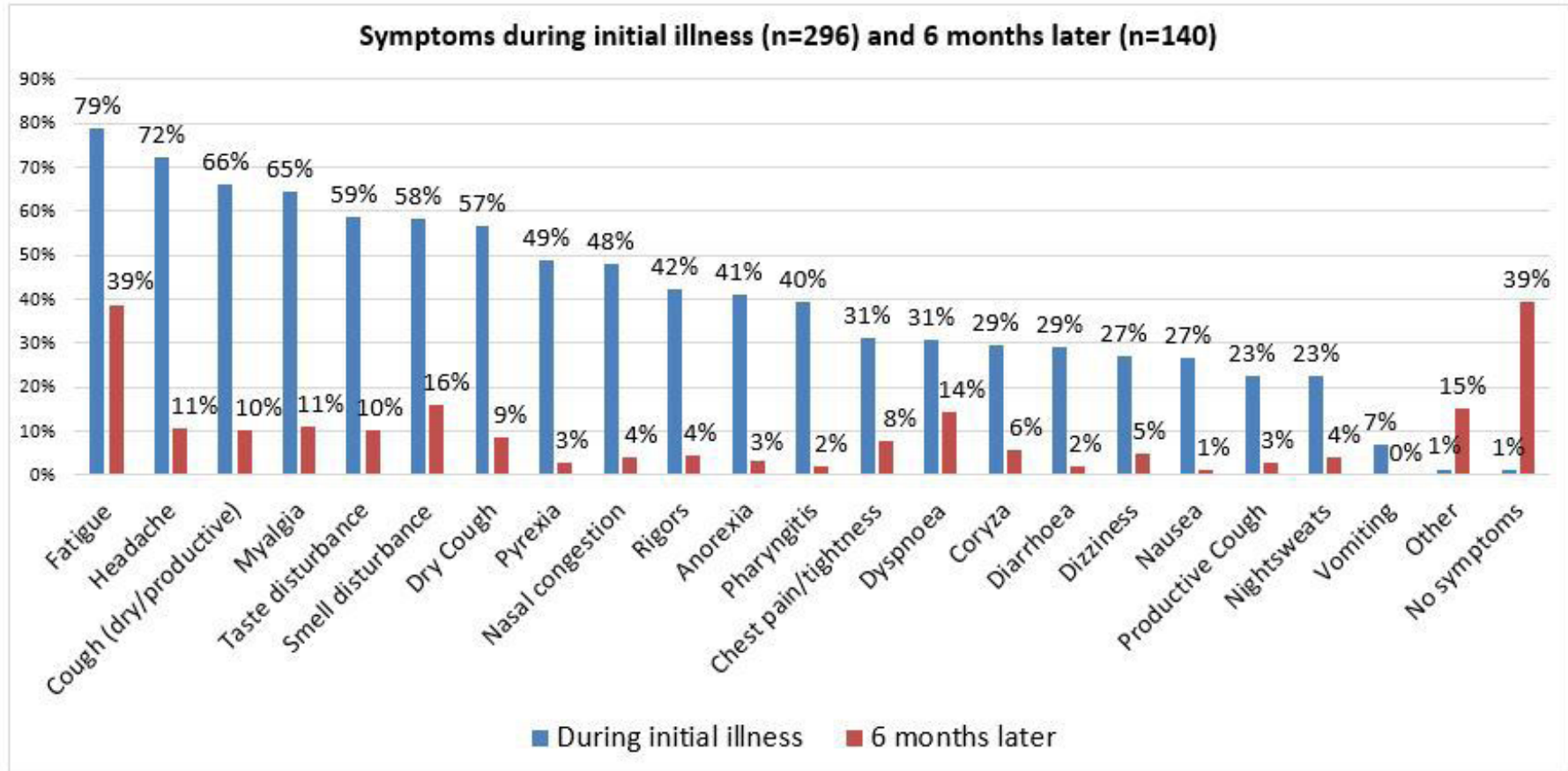

Figure 2 All symptoms were reported by individual participants during their acute illness (online check-in tool $n=296$ ) and 6 months later (feedback survey $n=140$ ).

Participants who used the tool $(\mathrm{n}=108)$ were asked to choose as many words as applicable from the list in figure 4 to describe the effect that receiving texts from the hospital had on them. 'Reassuring', 'useful' and 'helpful' were selected in $66 \%, 56 \%$ and $55 \%$ of responses, with 'distracting', 'worrying' and 'unhelpful' each mentioned in $1 \%$ of responses (figure 4 ).

Of those who used the online symptom check-in tool $(\mathrm{n}=108)$, figure 5 shows that $87 \%(94 / 108)$ used it each time they received a text from the hospital. Only 56\% $(61 / 108)$ knew that the online symptom check-in tool contained links to official Health Service Executive (Ireland's national public health service) COVID-19 information. The anonymous feedback survey also showed that $69 \%(75 / 108)$ of participants received a call from the COVID-19 team during the course of their illness. Of these participants $(n=75)$, all but one participant found it helpful to receive such a call. Calls were made to 'check-in' with patients if they reported worsening symptoms or shortness of breath on the symptom check-in tool, and to assess their need for further clinical evaluation.

Participants were also asked to rate, on a scale of 1-10, how 'useful', 'easy to use' and 'satisfied' they were with different aspects of the service, along with their perception of the overall quality of the service (figure 6). On

\section{Feedback survey responses $(n=140)$}

Did you find it inconvenient to receive texts from the hospital?

Did you use the online symptom check-in?

Did you call the COVID-19 phone line during your illness?

Did you receive a pulse oximeter from the hospital?

\begin{tabular}{|l|l|l|l|l|l|l|}
\hline $21 \%$ & \multicolumn{3}{|c|}{$79 \%$} \\
\hline & & & & & \\
\hline & & & & \\
\hline & \multicolumn{2}{|c|}{$77 \%$} & & \multicolumn{2}{|c|}{$23 \%$} \\
\hline & & & & & & \\
\hline & $53 \%$ & & & \multicolumn{3}{|c|}{$47 \%$} \\
\hline & & & & & \\
\hline & & & & \\
\hline
\end{tabular}

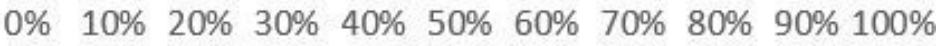
Yes No

Figure 3 Responses to feedback survey. 


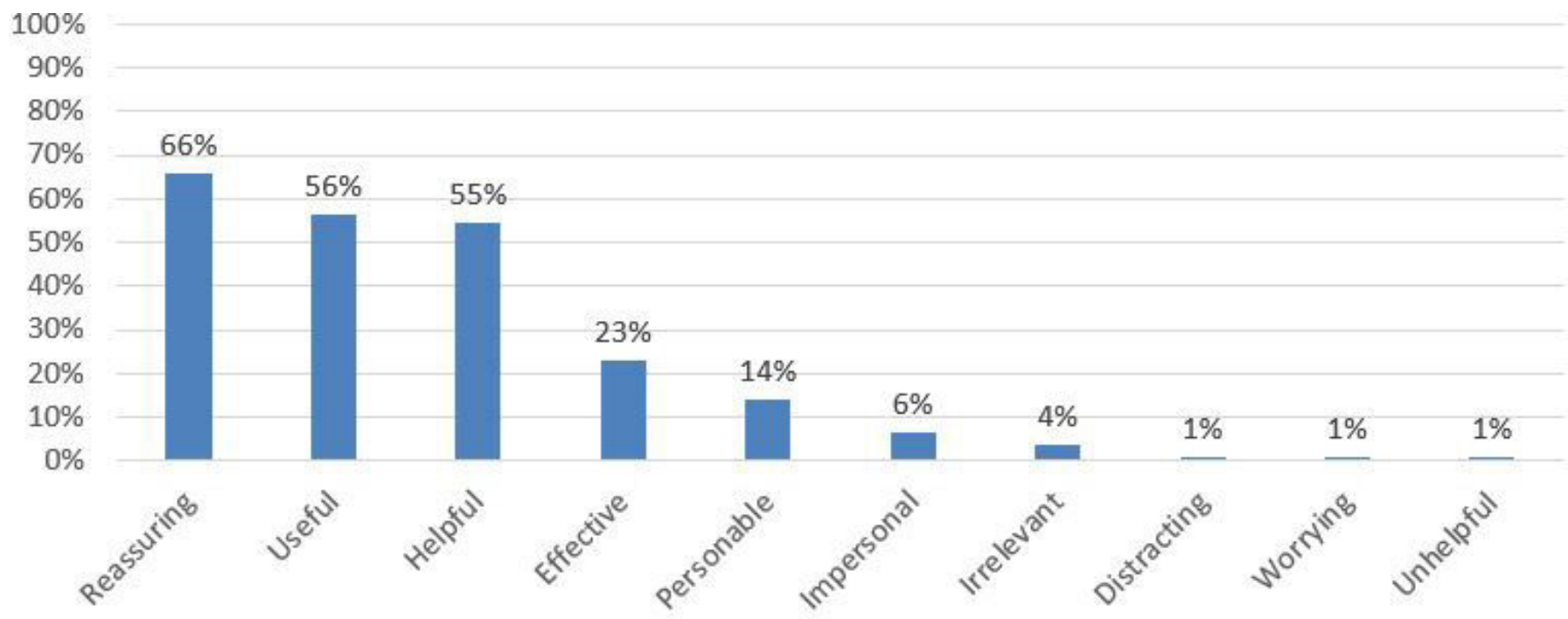

Figure 4 Words chosen by participants of the feedback survey to describe how receiving texts from the hospital for the online symptom check-in tool made them feel.

average, participants rated the usefulness of receiving a text with the COVID-19 phoneline number $(n=140)$ and links to official COVID-19 info $(n=61)$ at 8.5/10 and $8.1 / 10$, respectively. Satisfaction with the advice they received on calling the phone line $(n=74)$ was rated at $8.7 / 10$, and at $8.8 / 10$ for those who received a call from the COVID-19 team $(n=75)$. The ease of use of the pulse oximeter $(n=28)$ and the online symptom checker $(\mathrm{n}=108)$ was rated at $9.4 / 10$ and $8.7 / 10$, respectively. The overall quality of the service overall was rated at 8.5/10 $(\mathrm{n}=108)$. Of those who used the online symptom check-in $(n=108), 93 \%(100 / 108)$ agreed that they would use such a service again, with 3\% saying they would not and $4 \%$ saying they were unsure. Reasons given by those who did not use the online symptom check-in $(n=32)$ included feeling too unwell to use it $(1 / 32)$, forgetting about it $(5 / 32)$, feeling sufficiently informed by healthcare staff already (4/32) and feeling better and therefore not having a need to use it $(5 / 32)$.

\section{DISCUSSION}

Telehealth, defined as 'electronic and telecommunications technologies and services used to provide care and services at a distance, ${ }^{19}$ is an important frontline adjunct to traditional healthcare practices in helping to relieve pressure on health systems. Recent advances in telehealth have allowed telemedicine, the 'practice of medicine using technology to deliver care at a distance', to be more widely exercised. Clinicians have used telehealth and telemedicine to adapt their services to the new challenges posed by the COVID-19 pandemic, such as remote patient management in cardiology outpatient services. ${ }^{20}$ There is a growing body of research demonstrating the important

\section{Feedback responses $(n=108)$}

\section{Did you use the online symptom check-in each time you received the hospital text?}

Did you know that there were weblinks to official HSE COVID-19 info at the start of the online...

Did you receive a call from the COVID-19 team?

Did you find it helpful to receive a call $(n=75)$

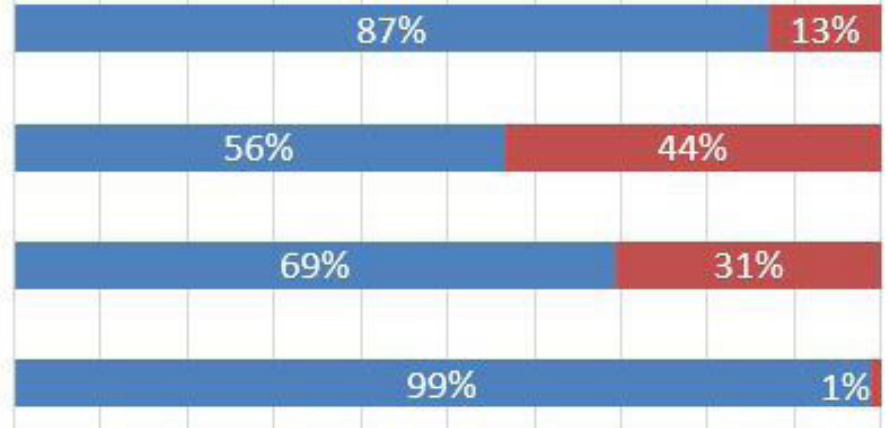

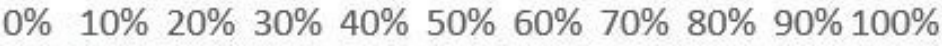
Yes $\square$ No

Figure 5 Feedback survey responses from those who completed the COVID-19 symptom check-in $(n=108)$. 
Average Rating (Scale 1 - 10)

\begin{abstract}
How useful did you find it to receive a text with the hospital's COVID-19 phoneline number? ( $n=140)$

How useful did you find it to have links to offical COVID-19 information in the symptom check-in tool? $(n=61)$
\end{abstract}

How satisfied were you with the advice you received from the medical team after you received a call from the COVID-19 medical team? $(n=75)$

How satisfied were you with the advice you received from the medical team after you called the COVID-19 phoneline? $(n=74)$

How easy to use was the pulse oximeter? $(n=28)$

How easy to use was the online COVID-19 symptom check-in tool? $(n=108)$

How would you rate the overall quality of this service? $(n=108)$

Figure 6 Participant feedback ratings.

strategic role played by telehealth (through the use of telehealth apps and technologies such as wearables for SpO2 monitoring) in directly combating the pandemic itself, especially with regard to the 3 Ts; tracking, testing and treating. ${ }^{21}$

This online symptom check-in tool is a further application of telehealth, developed in the face of the COVID-19 pandemic, that was intended to serve several purposes. Firstly, the tool was created to serve as a triage device for the increasing number of people (predominantly healthcare workers) who received a diagnosis of COVID-19 at the hospital and for whom an inpatient admission was not initially deemed necessary. The tool allowed for outpatients to be monitored remotely by the COVID-19 medical team via their responses to the online symptom check-in tool. Clinicians could identify patients that required further clinical follow-up via the breadth and severity of symptoms, demographics, comorbidities, reported by the patient. Patients identified as having a need for further follow-up were contacted to assess their clinical needs. Such patients were either managed over the phone, offered home pulse oximetry monitoring, invited for in-hospital assessment or advised to present immediately to the emergency department, as appropriate. Our results show that a slight worsening of symptoms was reported in $7 \%$ of responses to the check-in tool, with $1 \%$ of responses reporting a slight worsening of symptoms in the presence of dyspnoea at rest. No responses pertaining to severe worsening of symptoms were reported.

The tool made available to outpatients the phone number of the dedicated, clinician-manned in-hospital COVID-19 patient advice phone that the patient was advised to call if they had any COVID-19 related concerns. It helped to highlight to participants the red flag symptom of increasing breathlessness at rest associated with severe disease and prompted participants to contact the hospital or emergency services in the event they experienced these

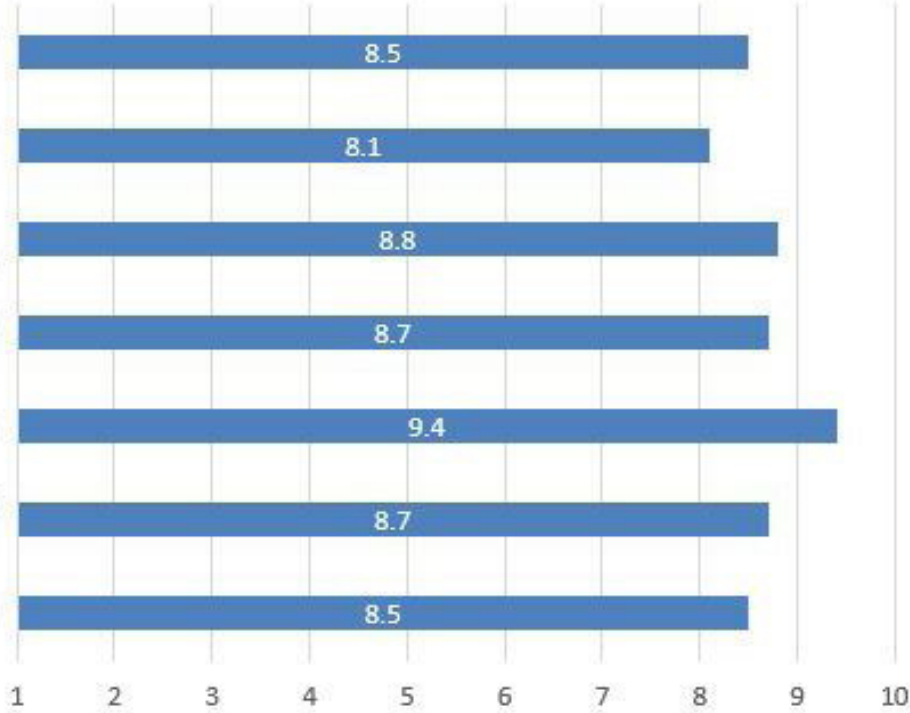

symptoms. One potential reason why no participants reported a severe worsening of their symptoms to the tool could be because the tool had prompted them to immediately call the COVID-19 patient advice phone or the emergency services at that point, though more research is required to further explore this theory. Seven check-in tool participants who reported slight worsening of their symptoms and/or shortness of breath at rest were identified by the clinicians staffing the dedicated COVID-19 patient advice phone and/or the online check-in tool as requiring in person medical assessment. Three of these participants were subsequently admitted to the hospital.

Overall, the system had high levels of engagement with a response rate of $>60 \%$ to texts sent to participants and with 296 individuals out of 413 contacted via text $(72 \%)$ completing the online symptom check-in tool at least once during their illness. The tool provided a weblink to online, national COVID-19 related health information sources that the participants could access if they so wished, something which is ever more important in the era of social media disinformation and 'Fake News'. ${ }^{22}$ This was intended to promote engagement and education on COVID-19. However, only $56 \%$ of those who used the online check-in tool were aware of this weblink to official information, and though those who were aware of this link found it useful, giving it an average rating of 8.1 out of 10 in terms of usefulness, more could be done to highlight this weblink in the future.

In addition to the testing of patients being cared for at the hospital, the hospital's occupational health department operated a busy COVID-19 swabbing hub for staff. Research by the PRECISE study group showed that $10.2 \%$ of the St. James's Hospital workforce had been diagnosed with COVID-19 by October 2020, ${ }^{23}$ with the majority of infections occurring during the first wave of the pandemic from March to June 2020. There was an expectancy that healthcare professionals would be heavily represented in 
the online check-in respondents and this is reflected in the responses to the tool. The large proportion of females and college/university educated participants also likely reflects the participation of healthcare workers.

Participants found the service overall to be 'useful' and 'easy to use'. The programme intervention was well received with high levels of satisfaction both from those who called the COVID-19 phoneline for advice and telephone assessment and from those who received calls from the COVID-19 team for advice and telephone assessment after their online symptom check-in responses were flagged. The overall quality of the service was found to be high among users and $93 \%$ said they would use such a service again in the future.

Another interesting outcome from this online symptom check-in tool relates to the findings in terms of frequency, range, and time of onset of different symptoms among this cohort of COVID-19 positive patients. Headache, fatigue and myalgia were the most frequently reported symptoms in the initial days of illness, none of which are currently included among the ECDC case definition clinical criteria symptoms (fever, cough, dyspnoea, smell/ taste disturbance) ${ }^{18}$ Fatigue and headache were reported more frequently overall than other symptoms. Two of the cardinal symptoms, taste and smell disturbance, appear to peak between days 5 and 8 postsymptom onset. This could have a negative effect on disease spread if testing is delayed until these symptoms are experienced. A significant number of responses reported nasal congestion $(\sim 1 / 3)$ and pharyngitis $(\sim 1 / 4)$ in their initial days of illness. Almost $10 \%$ of responses in the first 7 days of symptoms did not report any of the case defining criteria symptoms of COVID-19. These findings lend further weight to the case for screening people at high risk of COVID-19 disease in the absence of the current 'case defining' symptoms. Given the prevalence of symptoms such as fatigue, headache, myalgia, nasal congestion and pharyngitis in our participants, consideration should be given to adding these symptoms to the case defining criteria.

This research also shows the rate of symptom persistence, especially fatigue, smell disturbance and dyspnoea even after 6 months in this population of outpatients, $84 \%$ of whom did not have an inpatient stay during their illness. This finding chimes with other findings in the literature, where persistent anosmia ${ }^{24}$ and postviral fatigue have been seen commonly post-COVID-19 infection, irrespective of severity of initial illness. ${ }^{25}{ }^{26}$ Further research is warranted to investigate the cause and progression of these persistent symptoms associated with post-COVID-19 syndrome.

This system and research have a number of shortcomings, however. Firstly, a significant majority of participants had third-level (university/college) education $(79 \%$ according to the anonymous feedback survey), and the overwhelming majority of users of the online check-in tool were healthcare workers, therefore the engagement with the tool and anonymous feedback received may not be as representative of that of a more general outpatient population. However, at the very least, the research shows the value of this tool to an occupational health population. The system was designed to maximise accessibility, using SMS as a notification method. We explored several initial IT designs (eg, apps, chatbots, websites, etc) but opted for SMS to both maximise speed to implementation and accessibility (particularly among older and socially disadvantaged users). The symptom check-in tool link is included in typed format to allow those without smartphone internet access to complete the tool on another internet-connected device. However, the experience of clicking through the symptom check-in tool link does favour those with smartphone internet access. Both setups require a baseline level of technology literacy. The online system at present only exists in English and therefore may not be accessible to patients who do not speak English fluently. Similarly, the system may not be fully accessible to visually impaired patients and those with literacy issues. Further work is needed to provide similar levels of care to these vulnerable populations.

Though participation in the online COVID-19 symptom check-in was encouraging ( $72 \%$ of those contacted by text used the online check-in tool on at least one occasion), our results show that older patients, male patients and nonhealthcare workers were statistically less likely to use this service. Future implementations of this tool will require design changes to increase user uptake in these categories.

\section{CONCLUSION}

This online symptom check-in tool service for outpatient triage was found to be acceptable to patients with COVID-19, with high levels of engagement and satisfaction reported. It allowed for remote patient monitoring of outpatients with COVID-19 disease and provided links for patients to access official information on the disease as well as contact details for the in-house COVID-19 medical team if needed. It saw high levels of use among healthcare workers. This system also yielded interesting and valuable information on disease epidemiology among this cohort, highlighting the variety and persistence of symptoms experienced by patients during their acute illness and 6 months later. Additionally, this research showed that $8 \%$ of participant reponses did not exhibit any of the cardinal symptoms associated with the disease during the first 7 days of illness. This point lends weight to the debate on RT (reverse transcriptase)-PCR screening among high-risk populations (such as healthcare workers) and the expansion of test criteria, especially during times of high prevalence.

\section{Author affiliations}

${ }^{1}$ School of Medicine, Trinity College Dublin, Dublin, Ireland

${ }^{2}$ Genitourinary medicine and Infectious Diseases department (GUIDe), Saint James's Hospital, Dublin, Ireland

${ }^{3}$ Data Scientist, Cork, Ireland

${ }^{4}$ Information Management Systems, Saint James's Hospital, Dublin, Ireland

${ }^{5}$ Quality and Safety Directorate, Saint James's Hospital, Dublin, Ireland

${ }^{6}$ Department of Vascular Medicine and Surgery, Saint James's Hospital, Dublin,

Ireland

${ }^{7}$ Department of Occupational Health, Saint James's Hospital, Dublin, Ireland 
Contributors The subject matter of this paper was conceived by CK, SOR and $\mathrm{CB}$, and designed by $\mathrm{CK}, \mathrm{SOR}, \mathrm{GH}, \mathrm{DC}$ with oversight from UG and NN. Data was collected by CK, GH, DC, CC, MPC, ZM and CM. All parties contributed to the editing of this paper. CK is the lead author and guarantor of this paper.

Funding The authors have not declared a specific grant for this research from any funding agency in the public, commercial or not-for-profit sectors.

Competing interests None declared.

Patient consent for publication Not required.

Ethics approval Full ethical approval was granted for this research by the St. James's Hospital and Tallaght University Hospital ethics committee on 31/3/20 (REC: 2020-03 Chairman's Action (16))

Provenance and peer review Not commissioned; externally peer reviewed.

Data availability statement Data are available upon reasonable request. Data available from the corresponding author on request.

Supplemental material This content has been supplied by the author(s). It has not been vetted by BMJ Publishing Group Limited (BMJ) and may not have been peer-reviewed. Any opinions or recommendations discussed are solely those of the author(s) and are not endorsed by BMJ. BMJ disclaims all liability and responsibility arising from any reliance placed on the content. Where the content includes any translated material, BMJ does not warrant the accuracy and reliability of the translations (including but not limited to local regulations, clinical guidelines, terminology, drug names and drug dosages), and is not responsible for any error and/or omissions arising from translation and adaptation or otherwise.

Open access This is an open access article distributed in accordance with the Creative Commons Attribution Non Commercial (CC BY-NC 4.0) license, which permits others to distribute, remix, adapt, build upon this work non-commercially, and license their derivative works on different terms, provided the original work is properly cited, appropriate credit is given, any changes made indicated, and the use is non-commercial. See: http://creativecommons.org/licenses/by-nc/4.0/.

ORCID iD

Colm Kerr http://orcid.org/0000-0001-9976-8033

\section{REFERENCES}

1 Phelan AL, Katz R, Gostin LO. The novel coronavirus originating in Wuhan, China: challenges for global health governance. JAMA 2020;323:709-10.

2 World Health Organization. Statement on the second meeting of the International health regulations. emergency Committee regarding the outbreak of novel coronavirus (2019-nCoV), 2020.

3 World Health Organization. WHO Director-General's opening remarks at the media briefing on COVID-19-11 March 2020. Geneva, Switzerland, 2020.

4 Weiss $P$, Murdoch DR. Clinical course and mortality risk of severe COVID-19. The Lancet 2020;395:1014-5.

5 Zhou F, Yu T, Du R, et al. Clinical course and risk factors for mortality of adult inpatients with COVID-19 in Wuhan, China: a retrospective cohort study. Lancet 2020;395:1054-62.

6 Wu Z, McGoogan JM. Characteristics of and Important Lessons From the Coronavirus Disease 2019 (COVID-19) Outbreak in China:
Summary of a Report of 72314 Cases From the Chinese Center for Disease Control and Prevention. JAMA 2020;323:1239-42.

7 Grasselli G, Pesenti A, Cecconi M. Critical care utilization for the COVID-19 outbreak in Lombardy, Italy: early experience and forecast during an emergency response. JAMA 2020;323:1545-1546.

8 Porcheddu R, Serra C, Kelvin D, et al. Similarity in case fatality rates (cfr) of COVID-19/SARS-COV-2 in Italy and China. J Infect Dev Ctries 2020;14:125-8.

9 Chen J, Qi T, Liu L, et al. Clinical progression of patients with COVID-19 in Shanghai, China. J Infect 2020;80:e1-6.

$10 \mathrm{Ye} \mathrm{Q}$, Wang B, Mao J. The pathogenesis and treatment of the 'Cytokine Storm' in COVID-19. J Infect 2020;80:607-13.

11 Guan W-J, Ni Z-Y, Hu Y, et al. Clinical characteristics of coronavirus disease 2019 in China. N Engl J Med 2020;382:1708-20.

12 Reeves JJ, Hollandsworth HM, Torriani FJ, et al. Rapid response to COVID-19: health informatics support for outbreak management in an academic health system. J Am Med Inform Assoc 2020;27:853-9.

13 Judson TJ, Odisho AY, Neinstein AB, et al. Rapid design and implementation of an integrated patient self-triage and self-scheduling tool for COVID-19. J Am Med Inform Assoc 2020;27:860-6.

14 Wu C, Chen X, Cai Y, et al. Risk factors associated with acute respiratory distress syndrome and death in patients with coronavirus disease 2019 pneumonia in Wuhan, China. JAMA Intern Med 2020;180:934.

15 Chen N, Zhou M, Dong X, et al. Epidemiological and clinical characteristics of 99 cases of 2019 novel coronavirus pneumonia in Wuhan, China: a descriptive study. Lancet 2020;395:507-13.

16 World Health Organization. Clinical management of severe acute respiratory infection (SARI) when COVID-19 disease is suspected: interim guidance, 13 March 2020. World Health Organization, 2020.

17 Greenhalgh T, Koh GCH, Car J. Covid-19: a remote assessment in primary care. BMJ 2020;368:m1182.

18 Prevention ECfD, Control. Case definition and European surveillance for COVID-19, as of 2 March 2020, 2020.

19 Physicians AAoF. What's the difference between telemedicine and telehealth, 2020. Available: https://www aafp org/media-center/kits/ telemedicine-and-telehealth html [Accessed 8 Jun 2020].

20 Kerr B, Pharithi RB, Barrett M, et al. Changing to remote management of a community heart failure population during COVID-19 - Clinician and patient perspectives'. Int J Cardiol Heart Vasc 2020;31:100665.

21 Leite H, Gruber T, Hodgkinson IR. Flattening the infection curveunderstanding the role of telehealth in managing COVID-19. Leadership in Health Services, 2020.

22 O'Connor C, Murphy M. Going viral: doctors must tackle fake news in the covid-19 pandemic. BMJ 2020;369:m1587.

23 Allen N, Riain UN, Conlon N, et al. Prevalence of antibodies to SARS-CoV-2 in Irish Hospital healthcare workers. Epidemiol Infect 2021;149:1-33.

24 Carvalho-Schneider C, Laurent E, Lemaignen A, et al. Follow-Up of adults with noncritical COVID-19 two months after symptom onset. Clin Microbiol Infect 2021;27:258-63.

25 Townsend L, Dyer AH, Jones K, et al. Persistent fatigue following SARS-CoV-2 infection is common and independent of severity of initial infection. PLoS One 2020;15:e0240784.

26 Goërtz YMJ, Van Herck M, Delbressine JM, et al. Persistent symptoms 3 months after a SARS-CoV-2 infection: the post-COVID-19 syndrome? ERJ Open Res 2020;6. doi:10.1183/23120541.00542-2020. [Epub ahead of print: 2610 2020]. 